\title{
Duplication, divergence and persistence in the Phytochrome photoreceptor gene family of cottons (Gossypium spp.)
}

Ibrokhim Y Abdurakhmonov', Zabardast T Buriev', Carla Jo Logan-Young², Abdusattor Abdukarimov and Alan E Pepper*2

\begin{abstract}
Background: Phytochromes are a family of red/far-red photoreceptors that regulate a number of important developmental traits in cotton (Gossypium spp.), including plant architecture, fiber development, and photoperiodic flowering. Little is known about the composition and evolution of the phytochrome gene family in diploid (G. herbaceum, G. raimondii) or allotetraploid (G. hirsutum, G. barbadense) cotton species. The objective of this study was to obtain a preliminary inventory and molecular-evolutionary characterization of the phytochrome gene family in cotton.

Results: We used comparative sequence resources to design low-degeneracy PCR primers that amplify genomic sequence tags (GSTs) for members of the PHYA, PHYB/D, PHYC and PHYE gene sub-families from A- and D-genome diploid and AD-genome allotetraploid Gossypium species. We identified two paralogous PHYA genes (designated PHYA1 and PHYA2) in diploid cottons, the result of a Malvaceae-specific PHYA gene duplication that occurred approximately 14 million years ago (MYA), before the divergence of the A- and D-genome ancestors. We identified a single gene copy of $P H Y B, P H Y C$, and PHYE in diploid cottons. The allotetraploid genomes have largely retained the complete gene complements inherited from both of the diploid genome ancestors, with at least four PHYA genes and two genes encoding PHYB, PHYC and PHYE in the AD-genomes. We did not identify a PHYD gene in any cotton genomes examined.

Conclusions: Detailed sequence analysis suggests that phytochrome genes retained after duplication by segmental duplication and allopolyploidy appear to be evolving independently under a birth-and-death-process with strong purifying selection. Our study provides a preliminary phytochrome gene inventory that is necessary and sufficient for further characterization of the biological functions of each of the cotton phytochrome genes, and for the development of 'candidate gene' markers that are potentially useful for cotton improvement via modern marker-assisted selection strategies.
\end{abstract}

\section{Background}

Phytochromes are specialized photoreceptors that perceive and interpret light signals from the environment to regulate virtually all aspects of plant development, including seed germination, chloroplast development, tropisms, shade avoidance responses, floral initiation, circadian rhythms, pigmentation, and senescence [1-3]. The phytochromes have a primary role in sensing red $(\mathrm{R})$ and far-red (FR) light, and also play a role in the perception of

* Correspondence: apepper@bio.tamu.edu

2 Department of Biology, Texas A\&M University, College Station, Texas 77843, USA

Full list of author information is available at the end of the article blue (B) and ultraviolet (UV) light [4]. The active phytochrome molecule consists of a large $(\sim 110 \mathrm{kDa})$ apoprotein bound to a phycobilin chromophore $[5,6]$. The phytochrome apoproteins are encoded by a small gene family in all plant taxonomic divisions, including parasitic plants, mosses, cryptogams, and green algae [7-13]. In angiosperms, the phytochrome apoprotein genes have been classified into four or five gene sub-families based on sequence similarity to the five phytochrome genes of Arabidopsis: $P H Y A, P H Y B, P H Y C, P H Y D$, and PHYE $[14,15]$. All five Arabidopsis phytochromes share an amino acid sequence similarity of $46-56 \%$, with the 
exception $P H Y B$ and $P H Y D$--which are the result of recent gene duplication and share $\sim 80 \%$ amino acid identity $[14,16]$. Thus, the five Arabidopsis genes are often assigned to four subfamilies: $P H Y A, P H Y B / D, P H Y C$, and PHYE [17]. The Arabidopsis $P H Y B / D$ subfamily is more closely related to $P H Y E$ gene ( $55 \%$ nt identity) than to the PHYA and PHYC genes ( 47\% nt identity), which together form a separate ancient evolutionary clade $[13,14]$.

Having presumably arisen by gene duplication and subsequent subfunctionalization and/or neofunctionalization, the phytochrome gene family in toto performs a complex network of redundant, partially redundant, nonoverlapping, and in some cases antagonistic regulatory functions throughout plant development [18-35]. For example, all Arabidopsis phytochromes play diverse and interacting roles in photoperiodic regulation of floral initiation. $P H Y A, P H Y B, P H Y D$ and $P H Y E$ act partially redundantly in the light-dependent entrainment of the circadian clock $[35,36]$, which in turn regulates transcription of the floral inducer CONSTANS (CO) in a circadian manner [37]. In Arabidopsis, $P H Y A$, in conjunction with blue-light dependent cryptochrome photoreceptors $C R Y 1$ and $C R Y 2$, promotes flowering by inhibiting the degradation of $C O$ protein, while $P H Y B$ acts antagonistically to stimulate $C O$ degradation [38]. In addition, PHYB, PHYD and PHYE act partially redundantly as repressors of flowering that are dependent on R/FR ratio $[19,28,30,39]$. In this role, $P H Y B$ also acts downstream of $C O$ as a negative regulator of transcription of the 'florigen' molecule $F T$ (the target of $C O$ ) in a tissue specific manner [40]. Mutant analyses indicate that PHYC also plays a role in photoperiodic flowering [31,41]. Further, genetic variation at the $P H Y C$ locus underlies some of the natural phenotypic variation in flowering time in Arabidopsis $[42,43]$.

In angiosperms, the composition of phytochrome gene family varies significantly among taxonomic lineages. Although a single PHYA gene is present in most flowering plants, some plant families, such as carnation (Carryophyllaceae) and legumes (Fabaceae), have two distinct PHYA genes [10]. Similarly, several plant lineages have gained multiple $P H Y B$-like genes through independent gene duplications of $P H Y B[10,14,16,44-47]$. For example, tomato has two $P H Y B$ genes (designated $P H Y B 1$ and $P H Y B 2$ ) that are not directly orthologous to Arabidopsis $P H Y B$ and $P H Y D$, respectively [44]. While most angiosperms have a single $P H Y C$ gene, species in some families such as Fabaceae and Salicaceae appear to have lost PHYC during evolution [10,47]. Although a single PHYElike gene is present in most flowering plants, PHYE is completely absent in poplar (Salicaceae), in the Piperales, and some monocots such as maize [10,47]. Finally, the novel $P H Y F$ subfamily, which groups with $P H Y A / C$ clade, has been identified in tomato [44].

Little is known about the composition of the phytochrome gene family in cultivated cottons or their wild relatives (Gossypium spp.) in the Malvaceae family. This is despite the fact that physiological experiments suggest that phytochromes regulate economically important aspects of cotton development, including drought resistance, seed germination, plant architecture, photoperiodic flowering, and fiber elongation [48-51]. For example, $\mathrm{R} / \mathrm{FR}$ photon ratio influences the length and diameter of developing seed fiber; fibers exposed to a high R/FR photon ratio during development were longer than those that received lower $\mathrm{R} / \mathrm{FR}$ ratio, implicating the involvement of a phytochrome [50,51].

While modern domesticated varieties of the major cultivated cottons G. hirsutum L. and G. barbadense L. exhibit photoperiod independent flowering, wild and 'primitive' accessions of G. hirsutum and G. barbadense flower under short-day photoperiodic control [52,53]. An understanding of the molecular-genetic basis of differences in photoperiodic flowering in cottons will accelerate strategies for improvement of cultivated varieties through the introgression of valuable genetic traits from wild germplasm $[52,53]$. In this regard, it is important to note that mutational changes in phytochrome function have been implicated in the loss of photoperiod sensitivity in several major crops including sorghum, barley, rice, and soy [54-57].

A thorough characterization of the phytochrome gene family in cotton species is necessary for understanding the molecular basis of photoperiodic flowering, the influences of light quality on cotton fiber elongation, and other aspects of cotton development. Any inventory of phytochrome genes of cottons is complicated by the fact that the major cultivated species, G. hirsutum and G. barbadense are allotetraploids. Diploid species in the genus Gossypium are categorized into eight genome groups (designated A through G, and K) based on cytogenetic and phylogenetic criteria [58-62]. The old-world A genome group and the new world D genome group diverged from each other on the order of 1-7 MYA [61], then underwent hybridization and polyploidization creating an $\mathrm{AD}$ allopolyploid lineage ancestral to G. hirsutum (designated $\mathrm{AD}_{1}$ ) and G. barbadense (designated $\mathrm{AD}_{2}$ ) on the order of 1 MYA $[62,63]$.

In this study, we utilized a PCR-based approach with low-degeneracy primers to obtain gene fragments, or 'genome sequence tags' (GSTs) that yield an initial description of the composition and evolution of the phytochrome gene family in the New World allotetraploid cottons Gossypium hirsutum and G. barbadense, and in the Old-World diploids G herbaceum L. and G. raimondii 
Ulbr., which are considered to be extant relatives of the A- and D-genome diploid ancestors (respectively) of the allotetraploid lineage. This study provides a necessary foundation for studies of the specific biological functions of each of the phytochrome genes in cotton species, and helps to illuminate the evolutionary patterns of duplicated genes in complex genomes, as well as the evolutionary history of the world's most important fiber crop species.

\section{Results}

Because our results were derived from PCR, our inventory of the phytochrome gene family in Gossypium spp. is provisional. All sequences have been submitted to GenBank (accession numbers HM143735-HM143763).

\section{Phytochrome hinge amplification using 'universal' primers}

Between N-terminal 'photoperception domain' and Cterminal 'signaling domain' of the phytochrome apoprotein is a short 'hinge region' (Figure 1) that shows relatively high sequence variation, and has proven useful for characterization of the phytochrome gene complement in a variety of plant species, and for robust phylogenetic analyses [10]. To amplify the hinge region of all cotton phytochromes, we used an alignment of eudicot phytochrome sequences to design a 768-fold degenerate PCR primer (designated PHYdeg-F) based on the conserved HYPATDIP peptide in the $\mathrm{N}$-terminal domain, and a 16,384-fold degenerate PCR primer (designated PHYdeg$\mathrm{R})$, based on the conserved PFPLRYAC peptide in the Cterminal domain (Table 1).

Amplification across the hinge region using Taq DNA polymerase yielded PCR products from all taxa. We cloned the amplification products from each taxon into an E. coli vector, then sequenced $\sim 40$ clones for each taxon. For all taxa, a majority $(>60 \%)$ of clones showed the highest similarity in BLAST searches to Arabidopsis PHYE (E value 1e-40). For each taxon, only a minority of clones showed high-scoring similarity to Arabidopsis PHYA or PHYB. This apparently skewed distribution of amplification products -- observed across all taxa -- suggested an amplification bias in favor of PHYE amplicons. No clones were obtained from any taxon that had highscoring similarity to Arabidopsis PHYC or PHYD. No new phytochrome sub-families were observed.

\section{Amplification of the PHYA gene sub-family}

Because of possible biased amplification, we designed new less-degenerate hinge-region primer sets for the PHYA, $P H Y B / D$, and $P H Y C$ sub-families (Table 1) using available phytochrome sequences from species in the rosid clade, which includes both cotton and Arabidopsis $[64,65]$.

The hinge regions of $P H Y A$ genes were amplified using PHYABnondeg-F and PHYAdeg-R (Table 1), yielding a
360 bp amplification product from all accessions. In BLAST database searches, all clones had a high-scoring pair relationship with Arabidopsis PHYA ( $E$ value $\sim 2 \mathrm{e}^{-}$ $\left.{ }^{63}\right)$. Sequences from a total of more than 200 clones across all taxa yielded two distinct consensus contigs from each of the diploids G. herbaceum and G. raimondii, and four distinct contigs from the allotetraploids G. barbadense and G. hirsutum. When aligned across all taxa, these contigs yielded a $315 \mathrm{bp}$ consensus alignment that had an average pairwise sequence similarity of $94.6 \%$, with 282 sites (89.5\%) identical across all taxa, and no stop codons or indels in any taxa. Distance analysis (Figure 2) showed two well-separated gene sub-clades (100\% bootstrap support). These sub-clades were designated PHYA1 and PHYA2. The level of hinge-region differentiation between these two sub-clades was far greater than that seen in other cotton phytochrome gene sub-families (discussed below), with an uncorrected "p" distance of 0.086 , corresponding to $28 \mathrm{nt}$ changes (9\%) based on parsimony.

These data indicated that a single PHYA gene underwent duplication after the divergence of the cotton and Arabidopsis lineages, but prior to the divergence of Agenome and D-genome lineages, leaving each of the modern diploids in our study (and presumably the ancestors to the $\mathrm{AD}$ allotetraploids) with a complement of two PHYA paralogs (PHYA-1 and PHYA-2). Indeed, four distinct contigs were observed in both the inbred G. hirsutum cultivar TM-1 and in the doubled-haploid line G. barbadense 3-79. For each allotetraploid taxon, two contigs fell into each of the PHYA-1 and PHYA-2 clades (Figure 2). A conservative inventory of available EST sequences indicated that at least two distinct $P H Y A$ loci are expressed in G. hirsutum (Additional file 1).

Within each of the PHYA1 and PHYA2 clades, the level of nucleotide diversity was very low, with at most four parsimonious nucleotide changes separating each contig. However, within the PHYA1 clade, the contigs resolved into two subclades (74\% bootstrap support) that each contained a single contig from one of the diploid taxa and one contig from each of the allotetraploids. For example, G. raimondii (D-genome) PHYA1 grouped in a single contig from each of G. hirsutum and G. barbadense. Based on this grouping, the latter contigs were assigned the provisional designation of PHYA1.D. Similarly, G. herbaceum (A-genome) grouped with $G$. hirsutum PHYA1.A and G. barbadense PHYA1.A. Based on similar criteria, the PHYA2 clade was also divided into PHYA2.A and PHYA2.D subclades (90\% bootstrap support). The phylogenetic resolution of A- and D-genome subclades supported the hypothesis that each of the A- and Dgenome diploids contributed both PHYA1 and PHYA2 to the allotetraploid lineage. Thus, although hinge-region nucleotide diversity within each of the PHYA1 and PHYA2 clades was low, it was sufficient to resolve a tentative PHYA gene complement for each taxon, as well as the 
Table 1: Primers used to amplify cotton phytochrome gene family.

\begin{tabular}{|c|c|c|}
\hline Primer name & Sequence $5^{\prime}$ to $3^{\prime}$ & Fold-degeneracy \\
\hline PHYdeg-F & CAYTAYYCIGCIACIGAYATHCC & 768 \\
\hline PHYdeg-R & CRCAIGCRTAICKARIGGRWAIGG & 16,384 \\
\hline PHYABnondeg-F & GCATTATCCTGCTACTACTGATATT & 0 \\
\hline PHYAdeg-R & CAWGCATACCTWAGMGGRAAI & 64 \\
\hline PHYBdeg-R & AACAACIAIICCCCAIAGCCTCAT & 64 \\
\hline $1010-\mathrm{F}$ & GTTYTTGTTTAAGCARAACCG & 4 \\
\hline 1910-R & GAGTCWCKCAGAATAAGC & 4 \\
\hline 1910-F & AGCTTATTCTGMGWGACTC & 4 \\
\hline $2848-R$ & TAACCCKCTTRTTTGCAGTCA & 2 \\
\hline PHYC-1R-DFCI & GGTCCGCCTGATTGAGACTGC & 0 \\
\hline
\end{tabular}

I corresponds to inosine. $R, Y, M, K, S$, W correspond to the IUPAC-IUB ambiguity set.

pattern of gene inheritance through the allopolyploidization event.

\section{Amplification of the $P H Y B / D$ gene sub-family}

A $~ 320$ bp fragment from the $P H Y B / D$ hinge region was obtained by amplification using primers PHYABnondeg$\mathrm{F}$ and PHYBdeg-R (Table 1). Sequences from a total of 80 clones yielded a single consensus contig from each of the diploid cottons G. herbaceum and G. raimondii, and from the allotetraploid G. hirsutum. Two distinct contigs were assembled from clones derived from the allotetraploid $G$. barbadense. These clone sequences shared $\sim 85 \%$ nucleotide identity with the Arabidopsis $P H Y B$ gene and $~ 78 \%$ nt identity with Arabidopsis PHYD. All clones had a highscoring pair relationship with the Arabidopsis $P H Y B$ gene ( $E$ value $\left.\sim 1 \mathrm{e}^{-71}\right)$ as well as significant similarity to the Arabidopsis $P H Y D$ gene $\left(E\right.$ value $\sim 3 \mathrm{e}^{-55}$ ). Consensus sequences were aligned across all taxa, yielding a $319 \mathrm{bp}$ alignment with an average pairwise sequence similarity of $99.8 \%$, with 317 sites $(99.4 \%)$ identical across all taxa, no stop codons and no indels. Although these data indicated the presence of at least one PHYB gene in each of the Aand D-genome diploid plants and in G. hirsutum, and at least two genes $P H Y B$ genes in the G. barbadense, the low level of nucleotide differentiation observed within the hinge region yielded insufficient phylogenetic information to characterize the $P H Y B$ gene complement in any of the study taxa.
To obtain better resolution of the $P H Y B$ gene complement, additional low degeneracy primers 1010-F, 1910-F, 1910-R, and 2848-R (Table 1) were used along with primer PHYABnondeg-F to create a $2.1 \mathrm{~kb}$ long series of overlapping amplicons corresponding to approximately $1.8 \mathrm{~kb}$ of the Arabidopsis PHYB gene and extending from the hinge, through the first intron and into the second exon (Figure 1). After amplification, cloning and sequencing, the amplicons were assembled for each taxon. In all Gossypium taxa examined, the first intron was $\sim 300 \mathrm{bp}$ longer than the first intron of $P H Y B$ from Arabidopsis.

Unlike the other phytochrome amplicons, we detected a high frequency of putative PCR-mediated recombination events [66] within the PHYB2.1 kb fragment from amplifications using G. barbadense as template. The recombination detection algorithm RDP3 [67] identified a number of clones resulting from apparent recombination between the A-genome and D-genome derived homeologous sequences, with predicted breakpoints $(P=$ 0 ) between nucleotides 1000 and 1700 of the alignment. After omission of these recombinant clones, composite amplicon sequences from each taxon were aligned, creating a consensus alignment of 2,061 bp with $98.8 \%$ average pairwise similarity and 2,007 identical sites (97.4\%). Overall, the cotton $P H Y B$ genes shared $65 \%$ nucleotide identity with the Arabidopsis $P H Y B$ ortholog. No stop codons or indels were detected in exon sequences. A 2 bp putative deletion was observed in one contig (designated 


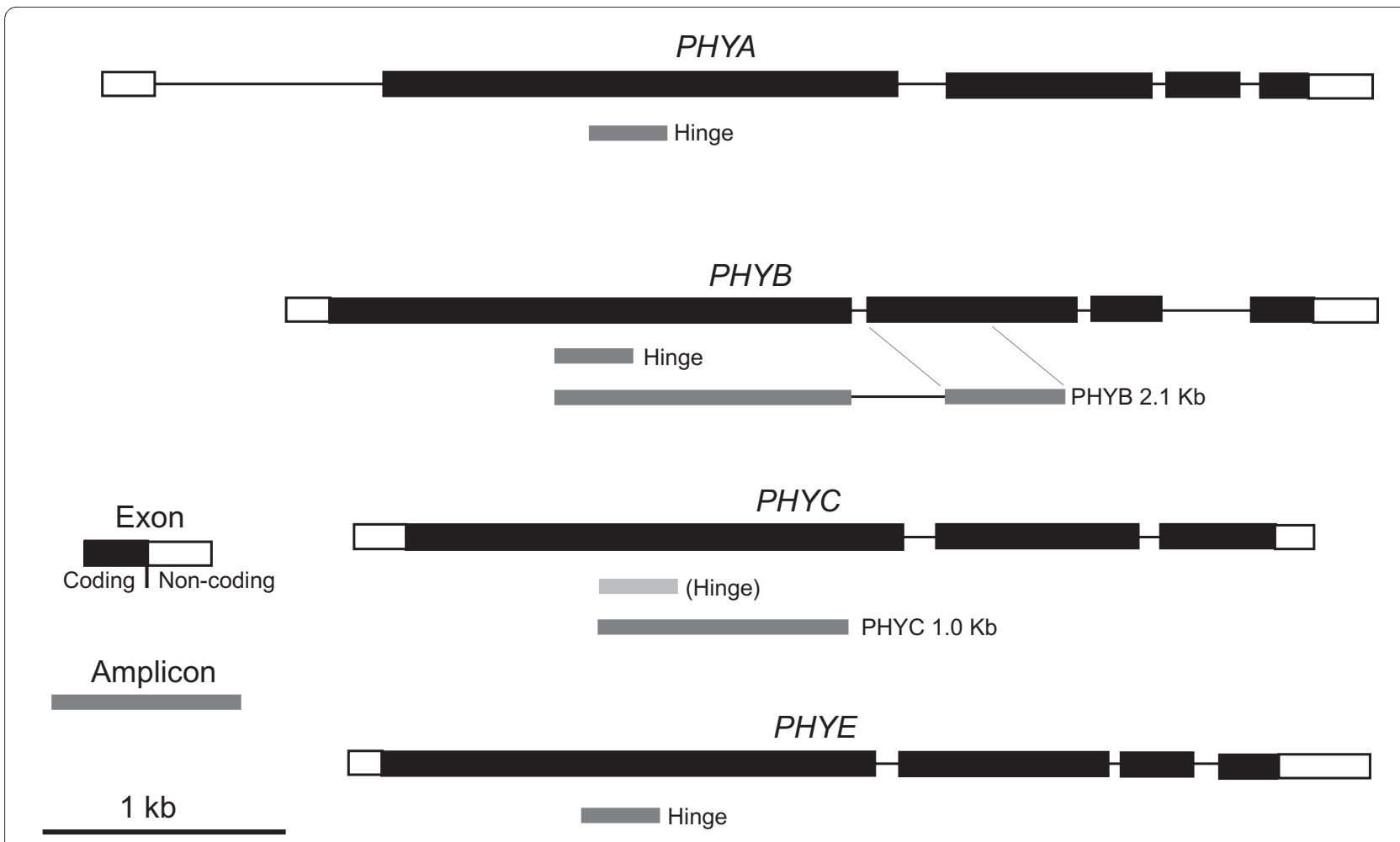

Figure 1 Gene diagrams and PCR amplicons used in this study. Model gene structures are derived from Arabidopsis thaliana annotations (At1 g09570, At2g18790. At5g35840, At4g18130). The PHYB $2.1 \mathrm{~kb}$ sequenced fragment represents a composite of several overlapping amplicons.

PHYB.D) from G. hirsutum. In addition, a 1 bp indel was polymorphic between the PHYB.A and PHYB.D clades. Finally, $P H Y B$ of $G$. raimondii had an additional $1 \mathrm{bp}$ insertion. All indel polymorphisms were located within first introns.

Detailed phylogenetic analyses of the 2,061 bp contigs from A-, D-, and AD-genome cottons (Figure 3 ) indicated the presence of least one $P H Y B$ locus in the two diploid cottons, G. herbaceum and G. raimondii, and at least two $P H Y B$ loci in both allotetraploid cottons. The G. hirsutum and $G$. barbadense sequence contigs each grouped into two sub-clades (tentatively designated PHYB.A and PHYB.D). The single $P H Y B$ contig from $G$. herbaceum was used to define the PHYB.A cluster (99\% bootstrap support), while the single $P H Y B$ contig from G. raimondii anchored the PHYB.D cluster. From these results, we concluded that PHYB.A and PHYB.D, which shared 98\% nucleotide sequence identity, arose as orthologs at the time of divergence of the A- and D-genome diploid lineages. We surmised that PHYB.A was contributed to the allotetraploids via the A-genome ancestor and PHYB.D was contributed via the $D$-genome ancestor. Available EST sequences indicated that at least one $P H Y B$ locus is expressed in G. hirsutum (Additional file 1).

\section{Amplification from the PHYC gene sub-family}

Several sets of degenerate primer pairs that were designed on the basis of the conserved HYPATDIP and
PFPLRYAC regions -- including several designed from rosid PHYC nucleotide sequences -- failed to produce detectable PCR amplification products from the Gossypium species tested (data not shown). However, the identification of a small EST clone (GenBank CO121409) with similarity to Arabidopsis $P H Y C\left(E\right.$ value $\left.=7 \mathrm{e}^{-119}\right)$ in a library from G. raimondii floral tissue [68], allowed us to design the primer PHYC_1R_DFCI within the C-terminal domain (Table 1). When used in combination with PHYdeg-F, this primer amplified a $\sim 1 \mathrm{~kb}$ fragment composed entirely of coding sequence from the first exon of $P H Y C$, including the hinge (Figure 1). All clones obtained using this primer pair had a high-scoring similarity to Arabidopsis PHYC (Evalue 1e $\left.\mathrm{e}^{-172}\right)$. From these clones, we assembled a single consensus contig from each of the diploid species G. herbaceum and G. raimondii, and two distinct consensus contigs from each of the allotetraploids G. hirsutum and G. barbadense. Consensus sequences for each of the putative $P H Y C$ contigs were aligned across all taxa, yielding a 1,022 bp alignment with an average pairwise sequence similarity of $99.1 \%, 1,002$ sites (98.0\%) identical across all taxa, with no indels or stop codons in any taxa.

In phylogenetic analyses (Figure 4), the PHYC consensus sequences grouped into two major clades (100\% bootstrap support). One of these clades contained the $G$. herbaceum contig and one contig from each of G. hirsutum and G. barbadense. This clade was designated 


\section{PHYA2}

\section{G.raimondii PHYA2}

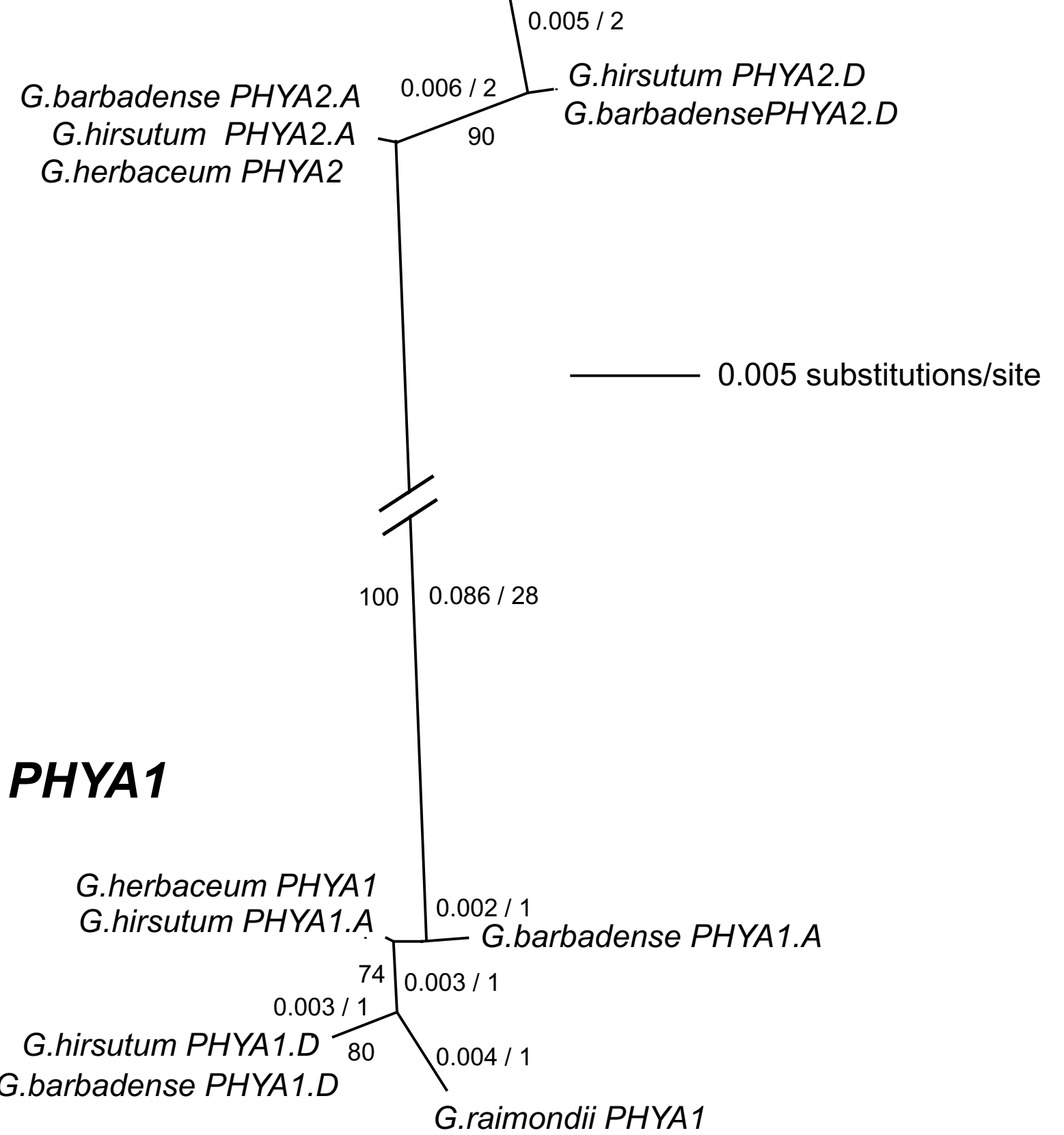

Figure 2 Unrooted NJ tree of Gossypium spp. PHYA-related genes based on a 315 bp consensus alignment of amplification products from the hinge region. Distances (uncorrected "p") and most parsimonious number of nt changes are indicated for each branch (to the left and to the right of the/, respectively). Branch lengths of less than 0.001 substitutions per site are not shown. Bootstrap support (500 replicates) is indicated where $>50 \%$.

PHYC.A. The other clade, designated PHYC.D, included the G. raimondii contig along with the other of the two contigs from each of G. hirsutum and G. barbadense. These data indicated that both the A- and D-genome ancestors had one PHYC gene, and that upon hybridization and polyploidization, this gene was contributed from each diploid to the allotetraploid ancestor of G. hirsutum and G. barbadense. 


\section{G. barbadense PHYB.A}

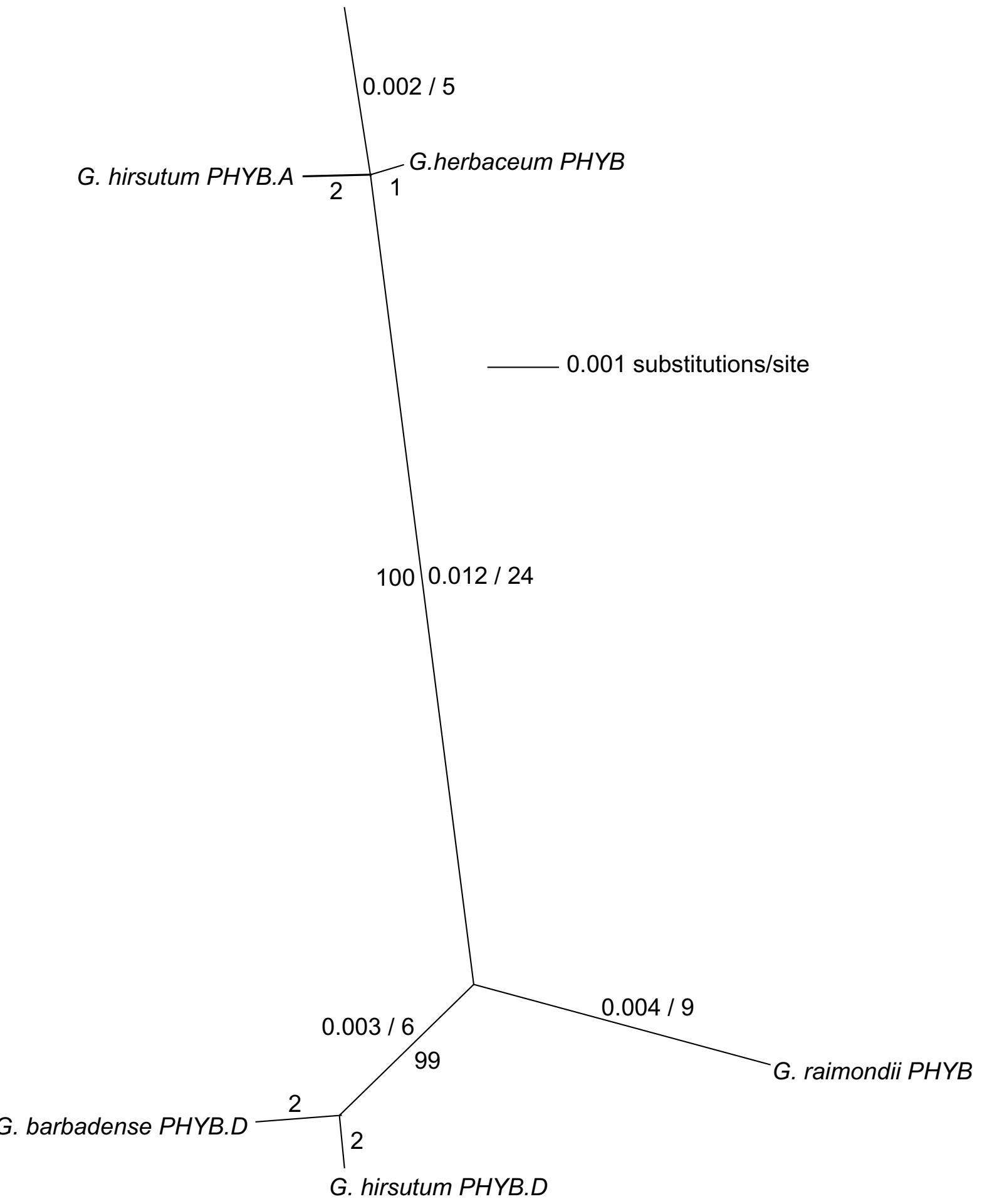

Figure 3 Unrooted NJ tree of Gossypium spp. PHYB-related genes based on the consensus alignment of the $\sim 2.1 \mathrm{~kb}$ merged amplicons. Distances (uncorrected "p") and most parsimonious number of nucleotide changes are indicated for each branch (to the left and to the right of the/ respectively). Branch lengths of less than 0.001 substitutions per site are not shown. Bootstrap support (500 replicates) is indicated where $>50 \%$. 


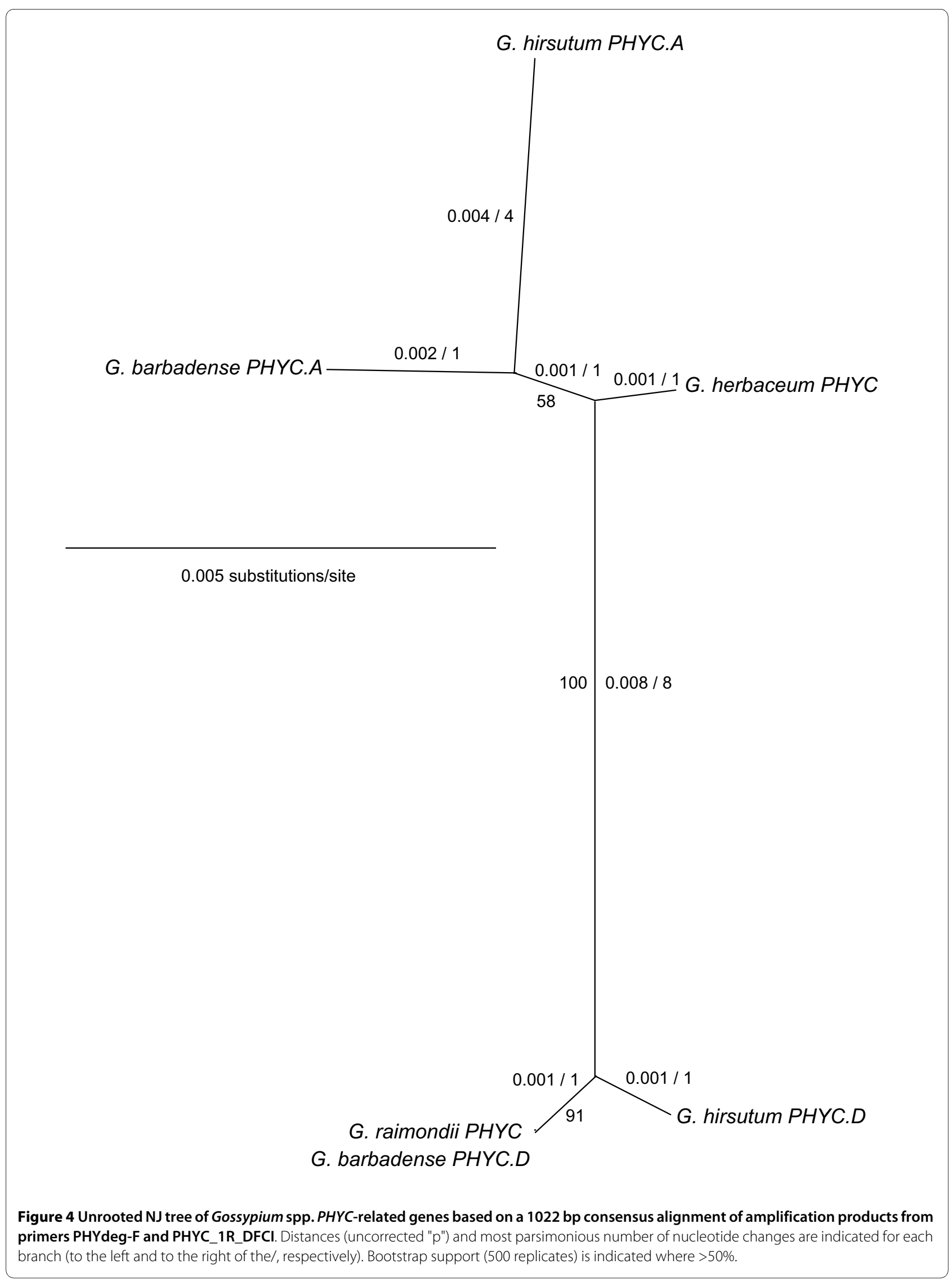


For comparison with the other phytochromes, we also analyzed a portion of the $P H Y C$ alignment corresponding to the hinge region only. This alignment was 296 nucleotide pairs in length, with pairwise sequence similarity of 99.0\%, 290 sites (98.0\%) identical across all taxa, with no indels. Although it encompassed fewer variable nucleotides, $\mathrm{NJ}$ analysis of the hinge region alone could be used to differentiate the PHYC.A and PHYC.D clades (100\% bootstrap support) and to infer the composition and evolutionary inheritance of the $P H Y C$ gene family in cottons (data not shown).

Our failure to obtain $P H Y C$ hinge amplification with several sets of both universal (e.g. PHYdeg-F/PHYdeg-R) and rosid specific primers was entirely due to substantial nucleotide differentiation in $P H Y C$, particularly within the hinge region. For example, the $24 \mathrm{nt}$ long PHYdeg- $\mathrm{R}$ primer had six nucleotide mismatches with the cotton PHYC genes, including three transitions and three transversions. Five of the six mismatches occurred at what are considered to be invariant (e.g. non-degenerate) nucleotide positions. It should be noted that these divergent nucleotides in the conserved primer-binding site did not alter the amino acid sequence (PFPLRYAC).

\section{The PHYE gene sub-family}

PHYE hinge region consensus contigs from our study taxa formed a $270 \mathrm{bp}$ alignment with an average pairwise similarity of $98.9 \%$, with 264 (97.8\%) invariant sites, no indels, and no stop codons in any taxa. The consensus of the aligned PHYE sequences had $80 \%$ nucleotide similarity to the corresponding fragment of the Arabidopsis PHYE gene. Based on maximum parsimony, nucleotide diversity in the cotton PHYE hinge sequences could be explained by a minimum of six nucleotide changes, all of which were synonymous. NJ analysis of the cotton PHYE hinge region showed two distinct clades (97\% bootstrap support) corresponding to the $\mathrm{A}$ - and D-genome derived orthologs (designated PHYE.A and PHYE.D), a finding consistent with a hypothesis in which each diploid ancestor contributed a single PHYE ortholog to the allotetraploid lineage (Figure 5). Interestingly, while two distinct PHYE contigs were obtained from G. hirsutum, only a single contig, which grouped with the D-genome clade, was obtained from G. barbadense. Available EST sequences indicated that at least one PHYE locus is expressed in G. hirsutum (Additional file 1).

A global hinge-based alignment of Arabidopsis and cotton phytochromes

PHYA, PHYB, PHYC and PHYE hinge regions from Arabidopsis and Gossypium spp. were aligned to create a global phytochrome alignment 358 nucleotides in length, with an average pairwise similarity of $69.4 \%$ and 123 identical sites $(34.4 \%)$. The gene phylogeny generated from this alignment (Figure 6) reflected divergence of $P H Y A$, PHYB, PHYC and PHYE as a result of speciation (nodes $1 \mathrm{~A}, 1 \mathrm{~B}, 1 \mathrm{C}$ and $1 \mathrm{E}$, respectively) and gene duplication (nodes 2 and 3). The level of nucleotide divergence of each of the gene sub-families after nodes $1 \mathrm{~A}, 1 \mathrm{~B}, 1 \mathrm{C}$ and 1E (Kimura 2-parameter distances) was similar, with a mean of $0.297 \pm 0.21$ nucleotide substitutions per site. However, the synonymous $\left(K_{S}\right)$ and non-synonymous $\left(K_{A}\right)$ substitution rates were both significantly more variable among the various gene sub-families defined by nodes $1 \mathrm{~A}, 1 \mathrm{~B}, 1 \mathrm{C}$ and $1 \mathrm{D}$ than were simple nucleotide distances (Table 2). Despite this variation, all sub-families showed a $K_{A} / K_{S}$ ratio $<0.1$, implying that each remains under purifying selection for function. Further, excessively long branch-lengths, which are often found in pseudogenes, were not observed. In the PHYB, PHYC and PHYE clades, the branch lengths leading to the Arabidopsis orthologs, which have known biological functions, were longer than the branches leading to their respective cotton orthologs. Considered together, these lines of evidence indicate that each of the phytochrome sub-families retains some biological function in Gossypium, as they do in Arabidopsis [14-16,18-31]. Further, our topology supports the conclusion that $P H Y D$ is the result of a relatively recent gene duplication that may be exclusive to the Brassicaceae family [16].

\section{Discussion}

\section{Resolution of the phytochrome gene family}

In three out of four cases, we were able to successfully resolve the inventory and evolutionary relationships of the phytochrome genes in diploid and allotetraploid cottons using the hinge region only. This finding supports the general utility of employing the hinge region for identifying GSTs for phytochromes. In only one case (PHYB) was additional gene sequence required for sufficient phylogenetic resolution. In another case $(P H Y C)$, nucleotide divergence at a commonly used primer-binding site prevented the characterization of the hinge region by the typical strategy of using primers based on conserved flanking peptides HYPATDIP and PFPLRYAC. However, nucleotide diversity within the $P H Y C$ hinge region itself was sufficiently informative to resolve the pattern of evolutionary inheritance through allotetraploidization event.

The sequencing of phytochrome gene fragments from A- and D-genome diploids, as well as from AD allotetraploid taxa, provides an essential foundation for all subsequent analysis of phytochrome function and evolution in Gossypium. The sequenced fragments provide sufficient information (at least two diagnostic nucleotide characters) to unequivocally identify or 'tag' various orthologs, homeologs and paralogs, as well as monitor their patterns of nucleotide divergence, and trace their evolutionary 


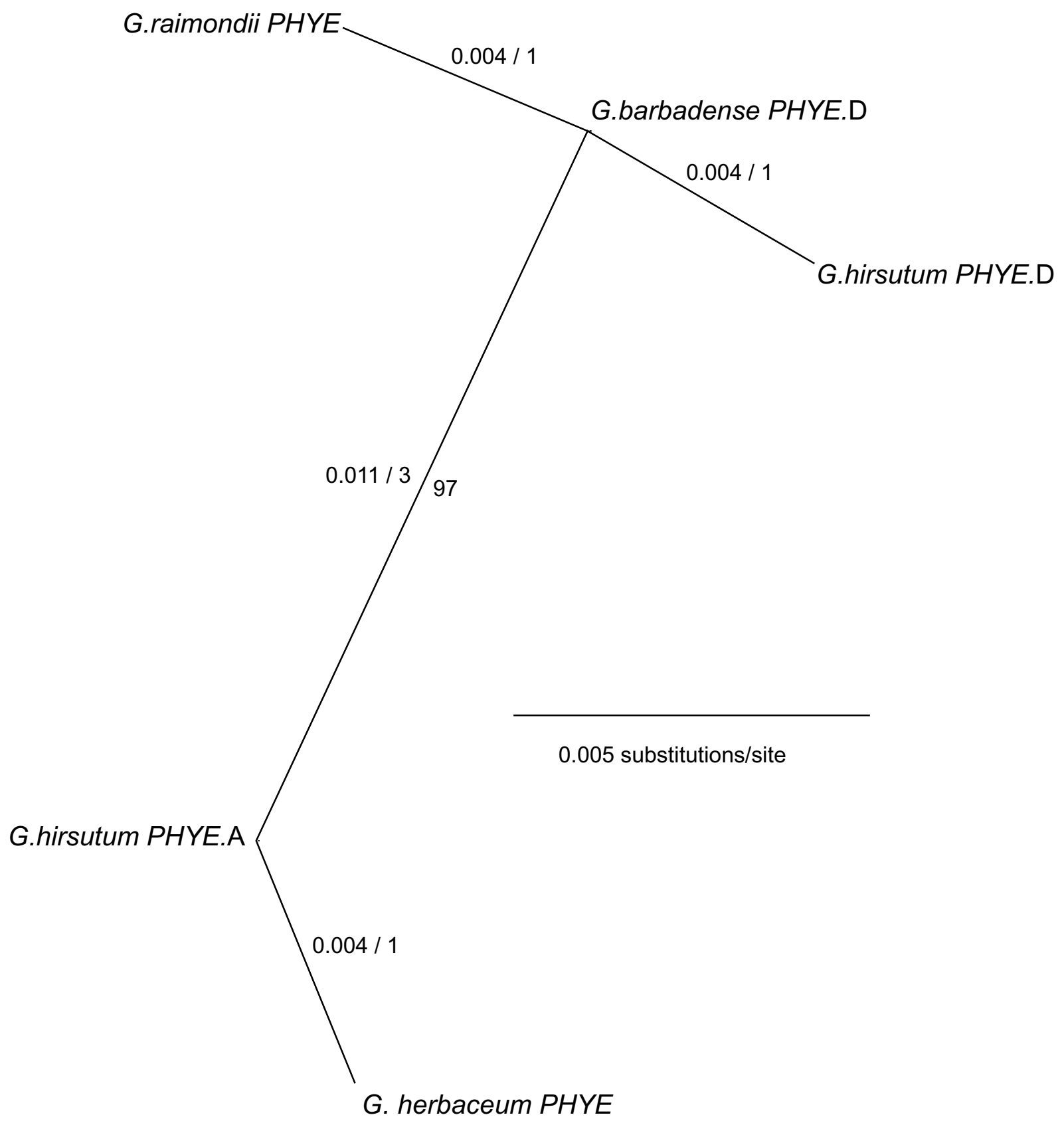

Figure 5 Unrooted NJ tree of Gossypium spp. PHYE-related genes based on a 270 bp consensus alignment of amplification products from the hinge region. Distances (uncorrected "p") and most parsimonious number of nucleotide changes are indicated for each branch. Branch lengths of less than 0.001 substitutions per site are not indicated. Bootstrap support (500 replicates) is indicated where $>50 \%$.

inheritance through the allopolyploidization event. This information will serve as a foundation for further sequence assembly and annotation, and will be used to design locus-specific primer sets for quantitative RT-PCR assays that will measure transcript levels for each gene family member. In some cases (e.g. PHYA1 vs. PHYA2) levels of sequence divergence are high enough to support studies of gene function using RNAi or amiRNA approaches to create gene-specific knockouts [69]. The use of well characterized 'candidate genes' of agronomic interest is becoming an integral component of markerassisted selection efforts in plants [70]. Several SNPbased molecular markers [71,72] are now being developed using the diagnostic nucleotide characters identi- 
Table 2: Nucleotide divergence in phytochrome genes in comparisons of Arabidopsis and cotton

\begin{tabular}{|c|c|c|c|c|c|c|}
\hline & $K-2 P$ & S Dif & $K_{s}$ & NS Dif & $K_{A}$ & $\mathrm{Ka} / \mathrm{Ks}$ \\
\hline Node $1 \mathrm{~A}$ & 0.291 & 46.5 & 1.82 & 27.4 & 0.123 & 0.068 \\
\hline Node 1B & 0.296 & 36.5 & 1.00 & 17.5 & 0.086 & 0.090 \\
\hline Node $1 \mathrm{C}$ & 0.274 & 41.0 & 1.55 & 30.3 & 0.147 & 0.095 \\
\hline Node 1E & 0.326 & 49.0 & $>2.0$ & 23.0 & 0.122 & $<0.061$ \\
\hline Node 3 & 0.094 & 17.0 & 0.309 & 11.8 & 0.050 & 0.163 \\
\hline
\end{tabular}

fied in this study, and are being mapped in experimental cotton populations that show segregation of phytochrome-controlled traits such as fiber length and flowering time.

\section{The ancestral phytochrome gene complement of the Malvales and Brassicales}

Our study indicated that the diploid ancestors to the world's major fiber crops (G. hirsutum and G. barbadense) had a complement of phytochrome apoprotein genes that was very similar to that of the model plant Arabidopsis thaliana. This was not entirely unexpected given the relatively close phylogenetic relationship of the two lineages $[64,65]$. The most-simple evolutionary scenario is that the last common ancestor of Arabidopsis and cotton, possibly an arborescent species in the late Cretaceous period [65], had a phytochrome gene complement consisting of one functional gene in each of the $P H Y A$, PHYB/D, PHYC and PHYE subfamilies.

\section{PHYA duplication in Gossypium}

After the divergence of the Malvales and Brassicales, the ancestral $P H Y A$ gene underwent duplication resulting in the observed $P H Y A-1$ and $P H Y A-2$ paralogs of modern Gossypium spp. As the A- and D-genome diploids have both paralogs, the duplication event occurred prior to the divergence of the A- and D-genome lineages. Using 85 MYA (range 68 MYA to $96 \mathrm{MYA}$ ) as a rough estimate of the time of divergence of the Malvales and Brassicales [64,73], along with our observed $K_{s}$ of 1.82 in the PHYA hinge region in this time interval, we can derive a crude estimate of 0.011 substitutions/synonymous-site/million years, and an estimate of the time of PHYA duplication of $\sim 14$ MYA. This estimate places the duplication well within the crown group of Malvales and the Malvaceae family [65]. Given our time estimate, the PHYA duplication may be exclusive to the genus Gossypium, but would have occurred prior to the estimated time of divergence of the A and D genome groups [62]. As neither we nor others $[58,62,74]$ have observed evidence of additional nuclear gene duplications or chromosomal duplications in this time period, the $P H Y A$ event was likely a tandem or segmental duplication, rather than whole genome duplication.

After a gene duplication event, one of the two newly duplicated genes is theoretically unconstrained by selection for function, and is thus free to accumulate mutations leading to a pseudogene fate, subfunctionalization, or neofunctionalization [75-80]. Although we did not obtain definitive evidence of pseudogenic sequences in any of the phytochromes or taxa studied (e.g. no stop codons or frameshift mutations), we did observe significant variation in $K_{A} / K_{s}$ ratios in pairwise interspecific comparisons (discussed below), leaving open the possibility of pseudogene outcomes. Alternatively, one of the duplicated genes may undergo positive selection to gain a novel function (neofunctionalization). Further, duplicated gene-pairs may subdivide the function of ancestral gene (subfunctionalization). Perhaps the most intriguing fate, which has been observed empirically, but not yet explained in theory, is the situation in which both gene copies may be retained for a lengthy period under what appears to be purifying or negative selection $[79,80]$. One approach to understanding the evolutionary fates of duplicated genes is through an analysis of the signature of natural selection on amino acid encoding sequences.

Although the hinge regions of phytochromes display relatively high levels of nucleotide diversity [81], they do not evolve under neutrality. The hinge region participates in inter-domain communication in phytochrome molecules [82]. For example, phosphorylation of a serine residue in the PHYA hinge plays a likely role in regulating protein-protein interactions between phytochrome and downstream signal-transducing molecules [83]. Com- 


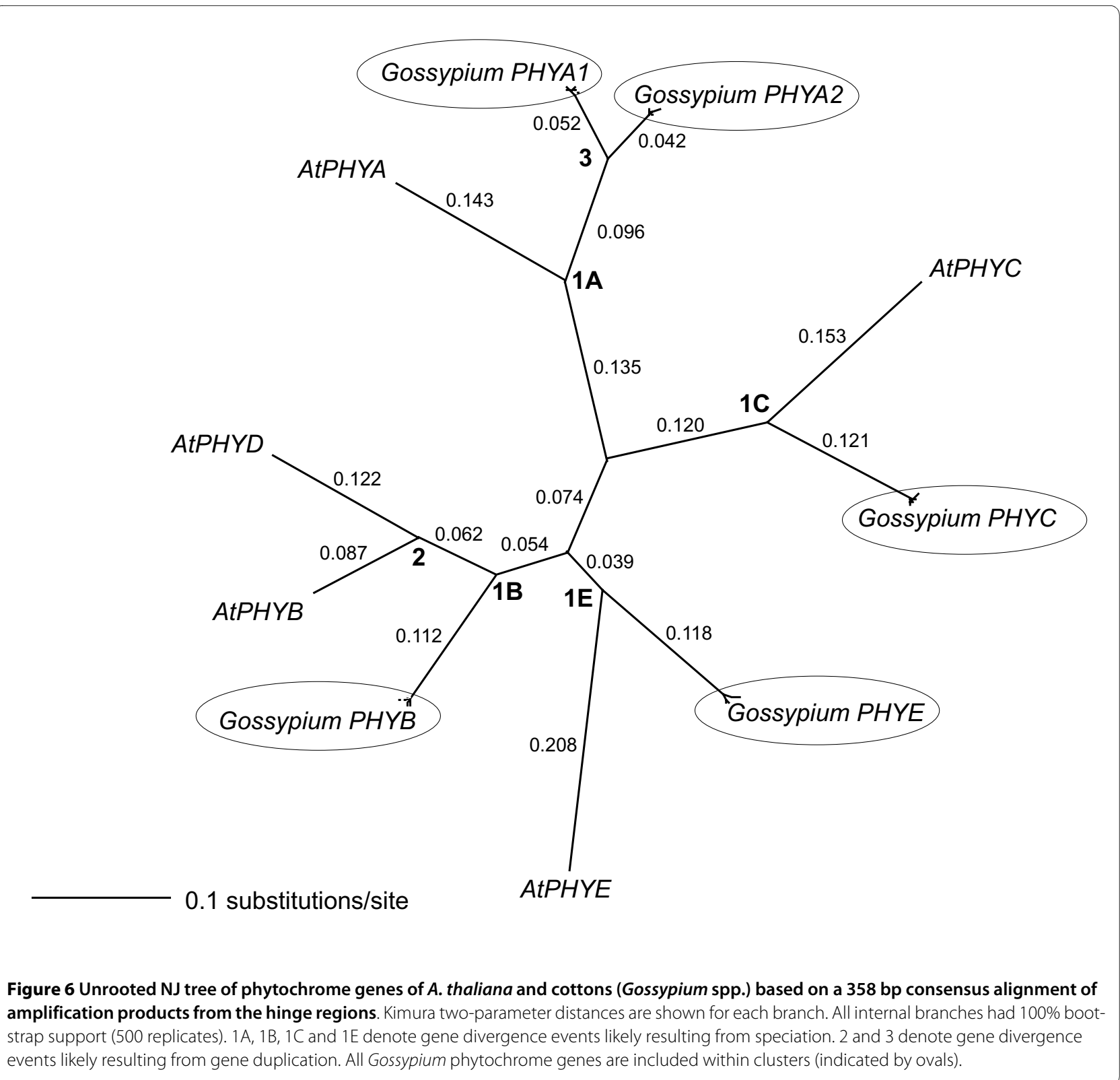

pared to wild-type, a mutation in the hinge region of Arabidopsis $P H Y B$ is deficient in localization into distinct nuclear bodies [84]. Further, a single nucleotide polymorphism (SNP) in the hinge of one of two PHYB genes in Aspen (Populus tremula, Salicaceae) was associated with natural geographic variation in the timing of bud-set [85].

In comparisons between cotton and Arabidopsis (Table 2 ), the $K_{A} / K_{s}$ ratio for the $P H Y A$ hinge region was 0.068 -a value that is typical for genes under purifying selection [86]. In contrast, the $\mathrm{K}_{\mathrm{A}} / \mathrm{K}_{\mathrm{s}}$ ratio for $P H Y A$ after gene duplication (node 3 ) was 0.163 , or $\sim 2.4$-fold higher. This value is also $\sim 2.1$-fold greater than the mean $K_{A} / K_{s}$ ratio of all phytochrome hinge regions (corresponding to nodes $1 \mathrm{~A}, 1 \mathrm{~B}, 1 \mathrm{C}$, and $1 \mathrm{D}$ in figure 6 ) of approximately
$0.079 \pm 0.014$. This significantly elevated $K_{A} / K_{s}$ ratio after the PHYA duplication could be attributed to a relaxation of stabilizing selection and/or subfunctionalization of the nascent PHYA paralogs (these two alternative possibilities are remarkably difficult to distinguish on the basis of sequence information alone).

The possible functional divergence of PHYA1 and PHYA 2 may be more pronounced after the separation of the A- and D-genome lineages (Table 3). A comparison of PHYA2 in the two diploids yields a $K_{A} / K_{S}$ ratio of $\sim 8.2$, primarily due to amino acid substitutions in PHYA2.D, while PHYA1 has a $K_{A} / K_{s}$ ratio of 0.000 in the same taxonomic comparisons. Although this difference is suggestive of possible differential rates of functional evolution in 
the paralogs, it is not statistically significant in Fisher's exact test $(P=0.2485)$. It will be of interest to determine whether the cotton PHYA paralogs have distinct functions. Experiments are underway to determine the respective biological functions of each $P H Y A-1$ and PHYA-2 in G. hirsutum and G. barbadense using paralogspecific RT-PCR, RNAi gene knockout, and tests for genetic associations between phytochrome-controlled phenotypic traits and PHYA-1 and PHYA-2 specific molecular markers. A 'candidate gene' approach has recently been used in soy (Glycine max) to uncover a genetic linkage between the photoperiod insensitivity locus E4 and one of the two the PHYA genes, designated GmphyA1 and GmphyA2 [57]. Loss of photoperiodic the major deleterious phenotypic effects that would have been caused by complete deficiency of PHYA gene function.

\section{Persistence and loss of phytochrome paralogs after allopolyploidization}

All phytochromes underwent gene duplication by polyploidization at the time of formation of the AD allotetraploids, on the order of 0.5-2.0 MYA [59,61,63,87]. For example, in G. hirsutum, we detected a minimum set of ten distinct phytochrome genes, including four PHYA genes. In order to assess the evolutionary trajectory of these recently duplicated genes, we examined the synonymous and non-synonymous divergence rates of A- and D-

Table 3: Nucleotide divergence in phytochrome genes in comparisons of A- and D-genome derived homeologs in diploid and allotetraploid cottons.

\begin{tabular}{|c|c|c|c|c|c|c|c|c|c|}
\hline Sequence & Comparison & S dif & S pos & $K_{s}$ & NS dif & NS pos & $K_{A}$ & $K_{A} / K_{s}$ & $P$ \\
\hline \multirow[t]{3}{*}{ PHYA1 Hinge } & D-D & 2.0 & 67.33 & 0.303 & 0.0 & 241.67 & 0.000 & 0.000 & 0.049 \\
\hline & D-T & 2.25 & 67.17 & 0.102 & 0.0 & 241.84 & 0.000 & 0.000 & 0.039 \\
\hline & $\mathrm{T}-\mathrm{T}$ & 2.5 & 67 & 0.038 & 0.0 & 242.00 & 0.000 & 0.000 & 0.030 \\
\hline \multirow[t]{3}{*}{ PHYA2 Hinge } & D-D & 1.0 & 66.42 & 0.015 & 3.0 & 242.58 & 0.125 & 8.224 & 0.622 \\
\hline & D-T & 1.0 & 66.38 & 0.015 & 2.0 & 242.63 & 0.065 & 4.247 & 0.504 \\
\hline & $\mathrm{T}-\mathrm{T}$ & 1.0 & 66.33 & 0.015 & 1.0 & 242.67 & 0.004 & 0.270 & 0.386 \\
\hline \multirow[t]{3}{*}{ PHYB 2.1 kb } & D-D & 8.0 & 377.33 & 0.022 & 7.0 & 1293.67 & 0.005 & 0.251 & 0.010 \\
\hline & D-T & 9.0 & 377.34 & 0.024 & 8.0 & 1293.63 & 0.006 & 0.256 & 0.006 \\
\hline & $\mathrm{T}-\mathrm{T}$ & 10 & 377.42 & 0.027 & 9.0 & 1293.58 & 0.007 & 0.300 & 0.004 \\
\hline \multirow[t]{3}{*}{ PHYC Hinge } & $D-D$ & 3.0 & 60.83 & 0.051 & 1.0 & 230.17 & 0.004 & 0.086 & 0.032 \\
\hline & D-T & 3.25 & 60.67 & 0.055 & 1.25 & 230.09 & 0.005 & 0.103 & 0.035 \\
\hline & $T-T$ & 3.5 & 60.5 & 0.06 & 1.5 & 230.00 & 0.007 & 0.119 & 0.038 \\
\hline \multirow[t]{3}{*}{ PHYC $1.0 \mathrm{~kb}$} & D-D & 7.0 & 224.67 & 0.032 & 3.0 & 795.33 & 0.004 & 0.120 & 0.002 \\
\hline & $\mathrm{D}-\mathrm{T}$ & 8.0 & 224.84 & 0.037 & 4.5 & 795.17 & 0.006 & 0.156 & 0.003 \\
\hline & $\mathrm{T}-\mathrm{T}$ & 9.0 & 225 & 0.041 & 6.0 & 795.00 & 0.008 & 0.184 & 0.002 \\
\hline \multirow[t]{3}{*}{ PHYE Hinge } & $D-D$ & 4.0 & 60.42 & 0.069 & 1.0 & 206.58 & 0.005 & 0.071 & 0.012 \\
\hline & $D-T$ & 3.75 & 60.46 & 0.065 & 0.5 & 206.54 & 0.003 & 0.042 & 0.015 \\
\hline & $\mathrm{T}-\mathrm{T}$ & 3.5 & 60.5 & 0.06 & 0.0 & 206.50 & 0.000 & 0.000 & 0.008 \\
\hline
\end{tabular}

D-D indicates means of comparisons within extant diploids, D-T indicates means of comparisons of extant diploids with tetraploids, T-T indicates means of comparisons within tetraploids. S dif, synonymous differences; $S$ pos, synonymous positions; NS dif, non-synonymous differences; NS pos, non-synonymous positions. $P$ indicates significance as determined by Fisher's exact test.

flowering is associated with a Ty1/copia-like retrotransposon insertion into exon 1 of GmphyA2. The authors argue that gene duplication and partial redundancy of the PHYA genes may have facilitated the loss of photoperiod sensitivity by allowing the GmphyA2 (E4) mutant to avoid genome phytochrome orthologs and homeologs (Table 3) in pairwise comparisons of 1) diploids with diploids (DD), 2) diploids with tetraploids (D-T), and 3) tetraploids with tetraploids (T-T). Given that the allotetraploid cottons had both A- and D-genome derived copies of each 
gene on the order of hundreds of thousands of years, we hypothesized that there may be a relaxation of selection in the allotetraploids, as one of the two copies should no longer be evolutionarily constrained.

However, in comparisons of A- vs. D-genome derived orthologs or homeologs for six GSTs (Table 3), we did not observe dramatic differences in $K_{A} / K_{s}$ between diploid and allotetraploids in any GST except the hinge region of PHYA2 (in this case, the observed $K_{A} / K_{S}$ ratio was actually $\sim 30$-fold higher in the extant diploids than in the allotetraploids). Because of low levels of nucleotide divergence, we employed Fisher's exact test [88] and found no significant differences in the patterns of nucleotide evolution in allotetraploids vs. diploids. Thus, there was no broad evidence of relaxation of natural selection on gene function after gene duplication by allotetraploidization. Further, the generally low $K_{A} / K_{s}$ ratios across all genes and taxa support a model in which that the phytochrome homeologs are largely evolving independently by a birth-and-death model rather than concerted evolution [89].

The coding sequences of the PHYB $2.1 \mathrm{~kb}$ fragment also appeared be evolving under stabilizing selection in both the diploids $\left(K_{A} / K_{s}=0.251\right)$ and allotetraploids $\left(K_{A} / K_{s}=\right.$ $0.300)$ reflecting continued selective constraint on coding sequence evolution after polyploidization. However, there was a significant excess of non-synonymous substitutions in both diploids and allotetraploids $(P=0.01$ and $P=0.004$, respectively, in Fisher's exact test) indicating a partial relaxation of negative selection and/or functional divergence of the $P H Y B$ homeologs.

In the allotetraploid cottons, both PHYC.A and PHYC.D are also evolving in a pattern consistent with purifying selection $\left(K_{A} / K_{s}=0.184\right.$ over 340 codons $)$. However, it should be noted that the PHYC.D clade appears to be evolving at distinctly faster rate (8 parsimonious substitutions, including 6 non-synonymous) than the PHYC.A clade (2 parsimonious substitutions, both synonymous). This suggests either a relaxation of purifying selection in, or functional divergence of PHYC.D. In a similar study of phytochromes in cultivated sorghum (Sorghum bicolor) and its wild congeneric relatives [90], $P H Y C$ was undergoing faster amino acid evolution than PHYA or PHYB. In the both the PHYB and PHYC gene subfamilies of cotton, the sequences of the C-terminal signaling domain had higher $K_{A} / K_{s}$ ratios than the corresponding hinge region alone. This may reflect the co-evolution of protein-protein interactions with downstream signaling partners, which are mediated by the C-terminal 'signal transduction' domain [1-6].

While PHYE-related contigs had low $K_{A} / K_{s}$ values (0.000 to 0.071$)$, indicating purifying selection, no contig corresponding to an expected G. barbadense PHYE.A ortholog was observed. This may have been due to undersampling of G. barbadense clones for sequencing, or due to nucleotide divergence in primer sites (as observed in PHYC). Of the 16 PHYE-like clone sequences obtained from G. barbadense, all were in the $\mathrm{D}$-genome derived clade, which would be an unlikely result $(P<0.005$, chisquare test) assuming equal amplification efficiencies for PHYE.A and PHYE.D. Alternatively, the apparent lack of a PHYE.A ortholog in G. barbadense could be explained by concerted evolution, gene conversion, or by PCRmediated recombination [66,87]. Overall, the PHYE genes, like the other cotton phytochromes, had more synonymous than non-synonymous nucleotide substitutions, favoring a birth-and-death model of gene evolution.

\section{Conclusions}

Our preliminary efforts to obtain an inventory of the cotton phytochrome gene family (based largely on 'hinge' region) indicated that diploid A- and D-genome diploid cottons have two paralogous $P H Y A$ genes (designated PHYA1 and PHYA2), and one each of PHYB, PHYC, and PHYE gene sub-families. Coding sequence evolution in PHYA2 was significantly elevated, suggesting loss of selection for function, or incipient subfunctionalization. Other than this duplication and the lack of a separate PHYD gene, the phytochrome complement of diploid cottons was very similar to that observed in the closely related model plant Arabidopsis thaliana, which greatly facilitates cross-species comparisons.

Whole genome duplication via allopolyploidization ( 0.5-2.0 MYA) resulted in additive amalgamation of phytochrome genes within a single nucleus in the allotetraploid, retaining complete gene complements of at least four PHYA genes, two genes of each PHYB, PHYC and PHYE in AD-genome G. hirsutum. G. barbadense may lack the PHYE gene contributed by the A-genome ancestor. Strong purifying selection on nearly all of the phytochrome genes suggests some level of conservation of function of each of the genes after polyploidization. With the possible exception of one of the PHYE.A homeologs in G. barbadense, we did not see evidence of gene loss. We did not observe any convincing evidence of concerted evolution by gene conversion. Rather, the genes duplicated by allopolyploidy appear to be largely retained, and evolving independently as observed in 48 other nuclear genes in allotetraploid cottons [86].

These results further our understanding of the evolutionary fates of duplicate genes following allopolyploidization. Information on key evolutionary events (such as duplications), as well as rates and patterns of evolutionary change, are an important component of the functional annotation of genes and genomes [91]. These data provide the foundation for more comprehensive 
studies of the biological functions of each of the cotton paralogs and homeologs. The development of phytochrome 'candidate gene' markers based on the GSTs identified here may prove useful in the mobilization of valuable genes from photoperiodic wild and primitive cottons into elite cotton varieties, in order to improve stress tolerance, disease resistance, fiber quality, and other traits.

\section{Methods \\ Plant Materials}

To simplify the assignment of sequences to orthologous or paralogous phytochrome loci (as opposed to alternative alleles at a single locus) we employed diploid and allotetraploid strains that were highly homozygous. Diploid cotton species G. raimondii Ulbr. and G. herbaceum L. were obtained from the cotton germplasm collection at the Institute of Genetics and Plant Experimental Biology, Tashkent, Uzbekistan. These lines had been maintained by selfing for multiple generations. Genetic standard genotypes G. hirsutum L. cv. TM-1 and G. barbadense L. cv. 3-79 were obtained from the USDA-ARS Cotton Germplasm Unit, at College Station, Texas, USA. G. hirsutum cv. TM-1 [92] is a highly inbred line ( $>40$ generations of selfing). G. barbadense cv. 3-79 is a doubled-haploid line [93].

\section{Genomic DNA isolation and PCR Amplification}

Genomic DNAs were isolated from fresh leaf tissue of individual plants from each taxon using the method described by Dellaporta et al. [94]. The primers used in this study (Table 1) were designed using sequences from phytochromes of dicotyledonous plants obtained from the GenBank database http://www.ncbi.nlm.nih.gov and aligned using CLUSTALX software [95]. These included the degenerate primer pair PHYdeg-F/PHYdeg-R, which was designed to amplify the hinge region of the entire phytochrome gene family, and primer pairs PHYABnondeg-F/PHYAdeg-R and PHYABnondeg-F/PHYBdeg-R, designed to amplify the hinge regions of the $P H Y A$ and $P H Y B / D$ subfamilies, respectively. In order to amplify additional regions of several the cotton phytochrome genes, degenerate primers that amplify amplicons downstream of the hinge region (in the C-terminal domain) were also designed using this approach. Conserved regions that had approximately $40-55 \% \mathrm{G}+\mathrm{C}$ content were used for primer design. The primer design criteria have been described [96].

PCR reactions were performed in a Robocycler thermocycler (Agilent, USA) with an initial denaturation cycle at $94^{\circ} \mathrm{C}$ for $3 \mathrm{~min}$., followed by 45 cycles of $94^{\circ} \mathrm{C}$ for $1 \mathrm{~min}$., $55^{\circ} \mathrm{C}$ for $1 \mathrm{~min}$. (annealing) and $72^{\circ} \mathrm{C}$ for $2 \mathrm{~min}$. (extension), followed by a single $5 \mathrm{~min}$. extension at $72^{\circ} \mathrm{C}$. A manual 'hot start' cycling protocol was performed through the addition of Thermus aquaticus (Taq) DNA polymerase in the annealing step of first cycle.

\section{DNA Sequence analyses}

PCR products were cloned into the vector $\mathrm{PCR} 4-\mathrm{TOPO}$ and transformed into $E$. coli TOP10 cells according to manufacturer's instructions (Invitrogen, USA). Cloning was necessary to resolve sequences of duplicated genes. Recombinant plasmids were purified by miniprep (Qiagen, USA) and sequenced using Big-Dye DNA version 1 cycle sequencing chemistry (Applied Biosystems, USA) along with vector-specific forward and reverse primers. As native Taq polymerase has an appreciable nucleotide substitution error rate [97], at least 10 clones were sequenced for each amplicon from each diploid taxon, and 20 clones were sequenced from each allotetraploid taxon. Unincorporated dye-labeled terminators were removed from the extension products by Bio-gel P-30 spin column purification (Bio-Rad, USA). Extension products were sequenced using the ABI 310 and ABI3130 Genetic Analyzers (Applied Biosystems, USA).

\section{Data analyses}

Double-stranded, finished sequences for each clone were assembled with Sequencher 4.8 software (Gene Codes, USA). After trimming of vector and amplification primers, sequences were searched against GenBank databases using BLASTN [98]. Searches of the non-redundant nucleotide database (nr) and the Arabidopsis thaliana database (Taxid: 3702 ) were performed using the "discontinuous megablast" method as implemented by the NCBI database [99]. Alignments of clones obtained from each amplicon/taxon combination were performed using ClustalX. Within each taxon, clone sequences were grouped into contigs on the basis of (in all cases) at least two shared diagnostic SNPs and (if present) shared indel polymorphisms. When a single clone differed from other clones in the same consensus contig at a single nucleotide position, these sporadic differences were assumed to be products of Taq polymerase substitution error [97].

Consensus sequences were then aligned across all taxa and used for phylogenetic analyses. Distance-based phylogenetic trees were generated using neighbor-joining [100], using a minimum evolution objective, with gaps (indels) ignored, and either uncorrected "p" distances or Kimura two-parameter distances [101], as noted in the figure legends. Parsimony analysis was performed by an exhaustive search implemented by the PAUP software package version 4.0b10 [102]. The robustness of each phylogenetic tree was evaluated by bootstrap replication [103]. Estimates of synonymous substitution rate $K_{S}$ and non-synonymous substitution rate $K_{A}$ were based the Jukes-Cantor correction [104] and calculated by the method of Nei and Gojobori [105] as implemented by the 
DnaSP ver. 5 software package [106]. The significance of differences in $K_{A}$ and $K_{S}$ were determined by Fisher's exact test [88]. Sequence alignments were scanned for possible recombination using the software package RDP3, employs a suite of recombination detection and analysis methods [67]. Phytochrome ESTs from Gossypium spp. were identified in GenBank by searching nonhuman, non-mouse ESTs (est_others) and Gossypium (Taxid: 3633) using the "discontinuous megablast" method as implemented by the NCBI database [99].

\section{Additional material}

\section{Additional file 1 A summary of phytochrome ESTs from Gossypium. A} summary of non-redundant, high-quality ESTs from the GenBank database, accessed on November 15, 2009. HSP: high scoring pair relationship with the corresponding Arabidopsis thaliana ortholog; Min loci: estimate of the minimum number of genomic loci identified by the ESTs (based on sequence differences).

\section{Abbreviations}

amiRNA: artificial micro-RNA; bp: base pair(s); FR: far-red light; indel: insertion/ deletion polymorphism; $K_{A}$ : non-synonymous nucleotide substitution rate; $k b$ : kilobase(s); kDa: kiloDalton; $K_{s}$ : synonymous nucleotide substitution rate; MYA: million years ago; NJ: neighbor joining; nt: nucleotide; PCR: polymerase chain reaction; R: red light; RNAi: RNA interference; SNP: single nucleotide polymorphism

\section{Authors' contributions}

IYA and AEP designed the experiment. IYA designed most of the PCR primers and cloned the PHYA, PHYB and PHYE gene families. ZTB performed DNA sequencing of phytochrome genes. CJLY isolated, cloned and sequenced the PHYC gene family and participated in the sequencing of PHYA, PHYB and PHYE genes. IYA, AA, CJLY, and AEP performed data interpretation and drafted the manuscript. All authors read and approved the final manuscript.

\section{Acknowledgements}

The UMID Presidential Fund of the Government of Uzbekistan provided support for the I.Y.A. to conduct research at Texas A\&M University. The USDA-ARS International Research Programs provided research grant support for this study under the project P-121. We acknowledge the help of the Science and Technology Center of Ukraine with the P-121 project coordination. CJLY was supported by a Texas A\&M University Regent's Fellowship and a Cotton Incorporated Fellowship (Project 08-380). We wish to thank Kostantin V. Krutovsky for helpful advice, Millie Burrell for critical reading of the manuscript, and Kamal M. El-Zik for his valued mentoring.

\section{Author Details}

${ }^{1}$ Center of Genomic Technologies, Academy of Sciences of Uzbekistan. Yuqor Yuz, Qibray region Tashkent, 111226 Uzbekistan and 2Department of Biology, Texas A\&M University, College Station, Texas 77843, USA

Received: 5 August 2009 Accepted: 20 June 2010

Published: 20 June 2010

\section{References}

1. Kendrick RE, Kronenberg GHM: Photomorphogenesis in plants 2nd edition. Kluwer Academic Publishers, Dordrecht, the Netherlands; 1994.

2. Quail PH: Photosensory perception and signal transduction in plants. Curr Opin Gen Dev 1994, 4:652-661.

3. Smith $\mathrm{H}$ : Physiological and Ecological Function within the Phytochrome Family. Annu Rev Plant Phys 1995, 46:289-315.

4. Chun L, Kawakami A, Christopher DA: Phytochrome A Mediates Blue Light and UV-A-Dependent Chloroplast Gene Transcription in Green Leaves. Plant Physiol 2001, 125:1957-1966.
5. Quail P: Phytochrome: a light-activated molecular switch that regulates plant gene expression. Annu Rev Genet 1991, 25:389-409.

6. Rockwell NC, Su YS, Lagarias JC: Phytochrome Structure And Signaling Mechanisms. Annu Rev Plant Phys 2006, 57:837-858.

7. Sharrock RA, Quail PH: Novel phytochrome sequences in Arabidopsis thaliana: structure, evolution, and differential expression of a plant regulatory photoreceptor family. Genes Dev 1989, 3:1745-1757.

8. Schneider-Poetsch HAW, Marx S, Kolukisaoglu HU, Hanelt S, Braun B: Phytochrome evolution: phytochrome genes in ferns and mosses. Physiol Plantarum 1994, 91:241-250.

9. Kolukisaoglu HU, Marx S, Wiegmann C, Hanelt S, Schneider-Poetsch HAW: Divergence of the phytochrome gene family predates angiosperm evolution and suggests that Selaginella and Equisetum arose prior to Psilotum. J Mol Evol 1995, 41:329-337.

10. Mathews S, Lavin M, Sharrock RA: Evolution of the phytochrome gene family and its utility for phylogenetic analyses of angiosperms. Ann Mo Bot Gard 1995, 82:296-321.

11. Wada M, Kanegae T, Nozue K, Fukuda S: Cryptogam phytochromes. Plant Cell Environ 1997, 20:685-690.

12. Wu SH, J Lagarias JC: The phytochrome photoreceptor in the green alga Mesotaenium caldariorum: implication for a conserved mechanism of phytochrome action. Plant Cell Environ 1997, 20:691-699.

13. Mathews S: Phytochrome Evolution in Green and Nongreen Plants. J Hered 2005, 96:197-204.

14. Clack T, Mathews S, Sharrock RA: The phytochrome family in Arabidopsis is encoded by five genes: the sequence and expression of $P H Y D$ and PHYE. Plant Mol Biol 1994, 25:413-27.

15. Cowl JS, Hartley N, Xie DX, Whitelam GC, Murphy GP, Harberd NP: The PHYC gene of Arabidopsis: absence of the third intron found in PHYA and PHYB. Plant Physiol 1994, 106:813-814

16. Mathews S, McBreen K: Phylogenetic relationships of B-related phytochromes in the Brassicaceae: Redundancy and the persistence of phytochrome D. Mol Phylogenet Evol 2008, 49:411-23.

17. Pratt LH: Phytochromes: differential properties, expression patterns and molecular evolution. Photochem Photobiol 1995, 61:10-21.

18. Devlin PF, Patel SR, Whitelam GC: Phytochrome E influences internode elongation and flowering time in Arabidopsis. Plant Cell 1998, 10:1479-1487.

19. Reed JW, Nagatani A, Elich TD, M Fagan M, Chory J: Phytochrome A and phytochrome B have overlapping but distinct functions in Arabidopsis development. Plant Physiol 1994, 104:1139-1149.

20. Shinomura T, Nagatani A, Chory J, Furuya M: The induction of seed germination in Arabidopsis thaliana is regulated principally by phytochrome B and secondarily by phytochrome A. Plant Physiol 1994, 104:363-371.

21. Botto F, Sanchez RA, Whitelam GC, Casal JJ: Phytochrome A Mediates the Promotion of Seed Germination by Very Low Fluences of Light and Canopy Shade Light in Arabidopsis. Plant Physiol 1996, 110:439-444

22. Furuya M, Schafer E: Photoperception and signaling of induction reactions by different phytochromes. Trends Plant Sci 1996, 1:301-307.

23. Casal JJ, Sanchez RA, Yanovsky MJ: The function of phytochrome A. Plant Cell Environ 1997, 20:813-819.

24. Smith $H, X y Y$, Quail PH: Antagonistic but Complementary Actions of Phytochromes A and B Allow Optimum Seedling De-Etiolation. Plant Physiol 1997, 114:637-641.

25. Qin M, Kuhn R, Moran S, Quail PH: Overexpressed phytochrome C has similar photosensory specificity to phytochrome $\mathrm{B}$ but a distinctive capacity to enhance primary leaf expansion. Plant J 1997, 12:1163-1172

26. Whitelam GC, Devlin PF: Roles of different phytochromes in Arabidopsis photomorphogenesis. Plant Cell Environ 1997, 20:752-758.

27. Neff MM, Chory J: Genetic Interactions between Phytochrome A Phytochrome B, and Cryptochrome 1 during Arabidopsis Development. Plant Physiol 1998, 118:27-35.

28. Devlin PF, Robson PRH, Patel SR, Samita R, Goosey L, Sharrock RA, Whitelam CG: Phytochrome D acts in the shade-avoidance syndrome in Arabidopsis by controlling elongation growth and flowering time. Plant Physiol 1999, 119:909-915.

29. Smith HB: Photoreceptors in Signal Transduction: Pathways of Enlightenment. Plant Cell 2000, 12:1-4

30. Franklin KA, Praekelt U, Stoddart WM, Billingham OE, Halliday KJ, Whitelam GC: Phytochromes B, D, and E Act Redundantly to Control Multiple 
Physiological Responses in Arabidopsis. Plant Physiol 2003, 131:1340-1346

31. Franklin KA, Davis SJ, Stoddart WM, Vierstra RD, Whitelam GC: Mutant Analyses Define Multiple Roles for Phytochrome C in Arabidopsis Photomorphogenesis. Plant Cell 2003, 15:1981-1989.

32. Franklin KA, Whitelam GC: Light signals, phytochromes and cross-talk with other environmental cues. J Exp Bot 2004, 55:271-276.

33. Josse EM, Foreman J, Halliday KJ: Paths through the phytochrome network. Plant Cell Environ 2008, 31:667-677.

34. Heschel MS, Butler CM, Barua D, Chiang GCK, Wheeler A, Sharrock RA, Whitelam GC, Donohue K: New Roles of Phytochromes during Seed Germination. Int J Plant Sci 2008, 169:531-540.

35. Somers DE, Devlin PF, Kay SA: Phytochromes and cryptochromes in the entrainment of the Arabidopsis circadian clock. Science 1998, 282:1488-1490.

36. Devlin PF, Kay SA: Cryptochromes are required for phytochrome signaling to the circadian clock but not for rhythmicity. The Plant Cell 2000, 12:2499-2509.

37. Suárez-López P, Wheatley K, Robson F, Onouchi H, Valverde F, Coupland $\mathrm{G}$ : CONSTANS mediates between the circadian clock and the control of flowering in Arabidopsis. Nature 2001, 410:1116-1120.

38. Valverde F, Mouradov A, Soppe W, Ravenscroft D, Samach A, Coupland G: Photoreceptor regulation of CONSTANS protein in photoperiodic flowering. Science 2004, 303:1003-1006.

39. Halliday KJ, Salter MG, Thingnaes E, Whitelam GC: Phytochrome control of flowering is temperature sensitive and correlates with expression of the floral integrator FT. Plant J 2003, 33:875-885.

40. Endo M, Nakamura S, Araki T, Mochizuki N, Nagatani A: Phytochrome B in the mesophyll delays flowering by suppressing FLOWERING LOCUST expression in Arabidopsis vascular bundles. Plant Cell 2005, 17:1941-1952

41. Monte E, Alonso JM, Ecker JR, Zhang Y, Li X, Young J, Austin-Phillips S, Quail PH: Isolation and characterization of phyC mutants in Arabidopsis reveals complex crosstalk between phytochrome signaling pathways. Plant Cell 2003, 15:1962-1980.

42. Balasubramanian S, Sureshkumar S, Agrawal M, Michael TP, Wessinger C, Maloof JN, Clark R, Warthmann N, Chory J, Weigel D: The PHYTOCHROME $C$ photoreceptor gene mediates natural variation in flowering and growth responses of Arabidopsis thaliana. Nat Genet 2006, 38:711-715.

43. Samis KE, Heath KD, Stinchcombe JR: Discordant longitudinal clines in flowering time and phytochrome $\mathrm{C}$ in Arabidopsis thaliana. Evolution 2008, 62:2971-2983.

44. Hauser BA, Cordonnier-Pratt MM, Daniel-Vedele F, Pratt LH: The phytochrome gene family in tomato includes a novel subfamily. Plant Mol Biol 1995, 29:1143-1155.

45. Pratt $\mathrm{LH}$, Cordonnier-Pratt MM, Hauser BA, Caboche M: Tomato contains two differentially expressed genes encoding B-type phytochromes neither of which can be considered an ortholog of Arabidopsis phytochrome B. Planta 1995, 197:203-206.

46. Pratt LH, Cordonnier-Pratt MM, Kelmenson PM, Lazarova GI, Kubota T, Alba $\mathrm{RM}$ : The phytochrome gene family in tomato (Solanum lycopersicum $\mathrm{L}$.). Plant Cell Environ 1997, 20:672-677.

47. Howe GT, Bucciaglia PA, Hackett WP, Furnier GR, Cordonnier-Pratt MM, Gardner G: Evidence that the phytochrome gene family in black cottonwood has one PHYA locus and two PHYB loci but lacks members of the PHYC/F and PHYE subfamilies. Mol Biol Evol 1998, 15:160-175.

48. Ouedraogo M, Hubac C: Effect of Far Red Light on Drought Resistance of Cotton. Plant Cell Physiol 1982, 23:1297-1303.

49. Singh G, Garg OP: Effect of red, far-red radiations on germination of cotton seed. Plant Cell Physiol 1971, 12:411-415.

50. Kasperbauer MJ: Cotton plant size and fiber developmental responses to FR/R ratio reflected from the soil surface. Physiol Plantarum 1994, 91:317-321.

51. Kasperbauer MJ: Cotton Fiber Length Is Affected by Far-Red Light Impinging on Developing Bolls. Crop Sci 2000, 40:1673-1678.

52. McCarty JC, Jenkins JN, Wu J: Primitive Accession Derived Germplasm by Cultivar Crosses as Sources for Cotton Improvement II. Genetic Effects and Genotypic Values. Crop Sci 2004, 44:1231-1235.

53. McCarty JC, Wu J, Jenkins JN: Genetic diversity for agronomic and fiber traits in day-neutral accessions derived from primitive cotton germplasm. Euphytica 2006, 148:283-293.
54. Childs KL, Miller FR, Cordonnier-Pratt MM, Pratt LH, Morgan PW, Mullet JE: The Sorghum photoperiod sensitivity gene $\mathrm{Ma}$, encodes a phytochrome B. Plant Physiol 1997, 97:714-719.

55. Hanumappa M, Pratt LH, Cordonnier-Pratt MM, Deitzer GF: A Photoperiod-Insensitive Barley Line Contains a Light-Labile Phytochrome B1. Plant Physiol 1999, 119:1033-1040.

56. Izawa T, Oikawa T, Tokutomi S, Okuno K, Shimamoto K: Phytochromes confer the photoperiodic control of flowering in rice (a short-day plant). Plant J 2000, 22:391-399.

57. Liu Kanazawa A, Matsumura H, Takahashi R, Harada J, Abe J: Genetic Redundancy in Soybean Photoresponses Associated With Duplication of the Phytochrome A Gene. Genetics 2008, 180:995-1007.

58. Endrizzi JE, Turcotte EL, Kohel RJ: Genetics, cytology and evolution of Gossypium. Adv Genet 1985, 23:271-375

59. Wendel JF: New World tetraploid cottons contain Old World cytoplasm. P Natl Acad Sci USA 1989, 86:4132-4136.

60. Wendel JF, Albert VA: Phylogenetics of the cotton genus (Gossypium): character-state weighted parsimony analysis of Chloroplast-DNA Restriction Site Data and Its Systematic and Biogeographic Implications. Syst Bot 1992, 17:115-143.

61. Wendel JF, Brubaker CL, Percival AE: Genetic diversity in Gossypium hirsutum and the origin of upland cotton. Am J Bot 1992, 79:1291-1310.

62. Cronn RC, Small RL, Haselkorn, Wendel JF: Rapid Diversification of the Cotton Genus (Gossypium: Malvaceae) Revealed by Analysis of Sixteen Nuclear and Chloroplast Genes. Am J Bot 2002, 89:707-725.

63. Senchina DS, Alvarez, Cronn RC, Liu B, Rong J, Noyes RD, Paterson AH, Wing RA, Wilkins TA, Wendel JF: Rate Variation Among Nuclear Genes and the Age of Polyploidy in Gossypium. Mol Biol Evol 2003, 20:633-643.

64. Soltis PS, Soltis DE, Chase MW: Angiosperm phylogeny inferred from multiple genes as a tool for comparative biology. Nature 1999, 402:402-404.

65. Wang H, Moore MJ, Soltis PS, Charles D, Bell CD, Brockington SF, Alexander R, Davis CC, Latvis MM, Manchester SR, Soltis DE: Rosid radiation and the rapid rise of angiosperm-dominated forests. P Natl Acad Sci USA 2009, 10:3853-3858

66. Cronn R, Cedroni M, Haselkorn T, Grover C, Wendel JF: PCR-mediated recombination in amplification products derived from polyploid cotton. Theor Appl Genet 2002, 104:482-489.

67. Martin DP, Williamson C, Posada D: RDP2: recombination detection and analysis from sequence alignments. Bioinformatics 2005, 21:260-262.

68. Udall JA, Swanson JM, Haller K, Rapp RA, (36 authors): A global assembly of cotton ESTs. Genome Res 2006, 16:441-450.

69. Ossowski S, Schwab R, Weigel D: Gene silencing in plants using artificial microRNAs and other small RNAs. Plant I 2008, 53:674-690.

70. Moose SP, Mumm RH: Molecular Plant Breeding as the Foundation for 21st Century Crop Improvement. Plant Physiol 2008, 147:969-977.

71. Konieczny A, Ausubel FM: A Procedure for mapping Arabidopsis mutations using co-dominant ecotype specific PCR-markers. Plant J 1993, 4:403-410.

72. Neff MM, Neff JD, Chory J, Pepper AE: dCAPS, a simple technique for the genetic analysis of single nucleotide polymorphisms: experimental applications in Arabidopsis thaliana genetics. Plant J 1998, 14:387-392.

73. Wikström N, Savolainen V, Chase MW: Evolution of the angiosperms: Calibrating the family tree. PRoy Soc London B 2001, 268:2211-2220.

74. Seelanan T, Schnabel A, Wendel JF: Congruence and consensus in the cotton tribe (Malvaceae). Syst Bot 1997, 22:259-290.

75. Ohno S: Evolution by gene duplication Springer-Verlag, New York, USA; 1970

76. Force A, Lynch M, Pickett FB, Amores A, Yan Y, Postlethwait J: Preservation of duplicate genes by complementary, degenerative mutations. Genetics 1999, 151:1531-1545.

77. Lynch M, Force A: The probability of duplicate gene preservation by subfunctionalization. Genetics 2000, 154:459-473.

78. Wagner A: Birth and death of duplicated genes in completely sequenced eukaryotes. Trends Genet 2001, 17:237-239.

79. Lynch M, Conery JS: The Evolutionary Fate and Consequences of Duplicate Genes. Science 2000, 290:1151-1155.

80. Moore RC, Purugganan MD: The evolutionary dynamics of plant duplicate genes. Curr Op Plant Biol 2005, 8:122-128.

81. Alba R, Kelmenson PM, Cordonnier-Pratt MM, Pratt LH: The Phytochrome Gene Family in Tomato and the Rapid Differential Evolution of this Family in Angiosperms. Mol Biol Evol 2000, 17:362-373. 
82. Park CM, Bhoo SH, Song PS: Inter-domain crosstalk in the phytochrome molecules. Semin Cell Dev Biol 2000, 11:449-456.

83. Kim JI, Shen Y, Han YJ, Park JE, Kirchenbauer D, Soh MS, Nagy F, Schäfer E, Song PS: Phytochrome phosphorylation modulates light signaling by influencing the protein-protein interaction. Plant Cell 2004, 16:2629-2640.

84. Chen M, Schwab R, Chory J: Characterization of the requirements for localization of phytochrome B to nuclear bodies. P Natl Acad Sci USA 2003, 100:14493-14498.

85. Ingvarsson PK, Garcia MV, Luquez V, Hall D, Jansson S: Nucleotide polymorphism and phenotypic associations within and around the phytochrome B2 locus in European aspen (Populus tremula, Salicaceae). Genetics 2008, 178:2217-2226.

86. Nekrutenko A, Makova KD, Li WH: The $K(\mathrm{~A}) / \mathrm{K}(\mathrm{S})$ ratio test for assessing the protein-coding potential of genomic regions: an empirical and simulation study. Genome Res 2002, 12:198-202.

87. Cronn RC, Small RL, Wendel JF: Duplicated genes evolve independently after polyploidy formation in cotton. P Natl Acad Sci USA 1999, 96:14406-14411.

88. Fisher RA: On the interpretation of $x^{2}$ from contingency tables, and the calculation of $P$. J Roy Stat Soc 1922, 85:87-94.

89. Nei M, Rogozin IB, Piontkivska H: Purifying selection and birth-anddeath evolution in the ubiquitin gene family. Proc Natl Acad Sci USA 2000, 97:10866-10871

90. White GM, Hamblin MT, Kresovich S: Molecular Evolution of the Phytochrome Gene Family in Sorghum: Changing Rates of Synonymous and Replacement Evolution. Mol Biol Evol 2004, 21:716-723.

91. Borevitz JO, Ecker JR: Plant Genomics: The Third Wave. Annu Rev Genom Hum G 2004, 5:443-477.

92. Kohel RJ, Richmond TR, Lewis CF: Texas Marker-1. A description of a genetic standard for Gossypium hirsutum L. Crop Sci 1970, 10:670-671.

93. Kohel RJ, Yu J, Park Y, Lazo GR: Molecular mapping and characterization of traits controlling fiber quality in cotton. Euphytica 2001, 121:163-172.

94. Dellaporta SL, Wood J, Hicks JP: A plant DNA minipreparation: Version II. Plant Mol Biol Rep 1983, 1:19-21.

95. Thompson JD, Gibson TJ, Plewniak F, Jeanmougin F, Higgins DG: The ClustalX windows interface: flexible strategies for multiple sequence alignment aided by quality analysis tools. Nucleic Acids Res 1997, 24:4876-4882

96. Reddy OUK, Pepper AE, Abdurakhmonov I, Saha S, Jenkins JN, Brooks T, Bolek Y, El-Zik K: New Dinucleotide and Trinucleotide Microsatellite Marker Resources for Cotton Genome Research. J Cotton Sci 2001, 5:103-113.

97. Eckert KA, Kunkel TA: High fidelity DNA synthesis by the Thermus aquaticus DNA polymerase. Nucleic Acids Res 1990, 18:3739-3744.

98. Altschul SF, Madden TL, Schäffer AA, Zhang J, Zhang Z, Miller W, Lipman DJ: Gapped BLAST and PSI-BLAST: a new generation of protein database search programs. Nucl Acids Res 1997, 25:3389-3402.

99. Ma B, Tromp J, Li M: PatternHunter: faster and more sensitive homology search. Bioinformatics 2002, 18:440-445.

100. Saitou N, Nei M: The neighbor-joining method: a new method for reconstructing phylogenetic trees. Mol Biol Evol 1987, 4:406-425.

101. Kimura M: A simple method for estimating evolutionary rate of base substitutions through comparative studies of nucleotide sequences. $J$ Mol Evol 1980, 16:111-120.

102. Swofford D: PAUP*: Phylogenetic Analysis Using Parsimony (and Other Methods). Version 4.0 Sinauer Associates, Sunderland, MA, USA; 2002.

103. Felsenstein J: Confidence limits on phylogenies: an approach using the bootstrap. Evolution 1985, 39:783-791.

104. Jukes TH, Cantor CR: Evolution of protein molecules. In Mammalian protein metabolism Edited by: Munro HN. Academic Press, New York, USA; 1969:21-123.

105. Nei M, Gojobori T: Simple methods for estimating the numbers of synonymous and nonsynonymous nucleotide substitutions. Mol Biol Evol 1986, 3:418-426.

106. Librado P, Rozas J: DnaSP v5: A software for comprehensive analysis of DNA polymorphism data. Bioinformatics 2009, 25:1451-1452. doi: 10.1186/1471-2229-10-119

Cite this article as: Abdurakhmonov et al., Duplication, divergence and persistence in the Phytochrome photoreceptor gene family of cottons (Gossypium spp.) BMC Plant Biology 2010, 10:119

\section{Submit your next manuscript to BioMed Central and take full advantage of:}

- Convenient online submission

- Thorough peer review

- No space constraints or color figure charges

- Immediate publication on acceptance

- Inclusion in PubMed, CAS, Scopus and Google Scholar

- Research which is freely available for redistribution

Submit your manuscript at www.biomedcentral.com/submit
C BioMed Central 